\title{
Are cognitive and educational development affected by age at which prophylactic therapy is given in acute lymphoblastic leukaemia?
}

\section{JANNOUN}

\author{
Department of Child Psychiatry, Hospital for Sick Children, London
}

SUMMARY Altogether 129 children with acute lymphoblastic leukaemia in remission, all of whom had completed treatment, were assessed using standardised intelligence and attainment tests. A control group of 67 healthy siblings was also assessed. Results showed that the patients were functioning within the average range of intelligence several years after completing treatment but that they had significantly lower intelligence quotients (IQs) than their siblings. Only patients who received cranial irradiation when aged 7 years or more were no different in intelligence from their siblings. Patients who were treated under the age of 3 years were found to have significantly lower IQs than patients who received the same treatment at an older age and a group of healthy children matched for age, sex, and parental occupation. This finding has practical implications for the management and education of younger patients with acute lymphoblastic leukaemia.

Results of previous studies have shown that children who have been treated for acute lymphoblastic leukaemia with a combination of chemotherapy and radiotherapy show greater intellectual impairment than children who have either not received radiotherapy or received delayed radiotherapy. ${ }^{1-3}$ Results of these studies strongly suggest that children treated for acute lymphoblastic leukaemia under the age of 5 years are more likely to be affected than children receiving the same treatment at an older age, but the numbers of patients studied were small, and results were obtained through post hoc analysis of the data. The present study was designed specifically to discover whether age at the time of irradiation of the central nervous system (CNS) may determine the extent to which a child's intellectual development and educational attainments are affected.

\section{Patients and methods}

Patients. Three groups of patients were selected from all the survivors of acute lymphoblastic leukaemia in 7 centres in the United Kingdom. The selection criteria were that the child had been treated for acute lymphoblastic leukaemia by a combination of chemotherapy and radiotherapy, that at the time of assessment the child was in remission and had not received treatment for at least 6 months, and that at the time of assessment the child was aged between 5 and 17 years. Group 1 included all survivors of acute lymphoblastic leukaemia who had received radiotherapy when less than 3 years old; 43 patients were identified and tested. Group 2 included 43 children randomly selected from survivors who had received the same treatment when aged between 3 and 6 years. Group 3 comprised 43 randomly selected children who had received treatment when aged 7 years or more. Each group was compared with a control group consisting of their own healthy siblings. Sixty seven siblings were assessed.

All patients had been treated on one of the Medical Research Council trials UKALL I-VI. ${ }^{45}$ All had received cranial irradiation simultaneously with intrathecal methotrexate, and those in UKALL I received intrathecal methotrexate for one year. Altogether 124 patients had received maintenance treatment for two to three years and five had had five years of treatment (three had bone marrow relapse and two had testicular relapse). Patients who had had a relapse were excluded from our analysis. Table 1 gives details of patients in groups 1,2 , and 3.

Psychological assessment. All subjects were assessed using the British Ability Scales (BAS), which provide measures of intellectual ability based on British norms. ${ }^{6}$ They include measures of reasoning ability (similarities, matrices), speed of information 
Table 1 Characteristics of patients with acute lymphoblastic leukaemia in remission (excluding relapsed patients) and of controls

\begin{tabular}{|c|c|c|c|c|c|c|}
\hline & \multicolumn{2}{|c|}{ No of patients } & \multirow{2}{*}{$\begin{array}{l}\text { Mean age at } \\
\text { diagnosis } \\
\text { (months) }\end{array}$} & \multirow{2}{*}{$\begin{array}{l}\text { Mean time (range) } \\
\text { receiving chemotherapy } \\
\text { (months) }\end{array}$} & \multirow{2}{*}{$\begin{array}{l}\text { Mean time (range) } \\
\text { since stopping treatment } \\
\text { (months) }\end{array}$} & \multirow{2}{*}{$\begin{array}{l}\text { Mean age (range) } \\
\text { at testing } \\
\text { (months) }\end{array}$} \\
\hline & Boys & Girls & & & & \\
\hline \multicolumn{7}{|c|}{ Patients } \\
\hline $\begin{array}{l}\text { Group } 1(n=40) \\
\text { Group } 2(n=41) \\
\text { Group } 3(n=41)\end{array}$ & $\begin{array}{l}22 \\
18 \\
17\end{array}$ & $\begin{array}{l}18 \\
23 \\
24\end{array}$ & $\begin{array}{l}25 \\
56 \\
109\end{array}$ & $\begin{array}{l}33(23-47) \\
32(24-42) \\
31(19-51)\end{array}$ & $\begin{array}{l}43(9-94) \\
31(7-72) \\
32(6-95)\end{array}$ & $\begin{array}{l}103(58-150) \\
120(78-170) \\
166(118-209)\end{array}$ \\
\hline $\begin{array}{l}\text { Group } 1(n=22) \\
\text { Group } 2(n=22) \\
\text { Group } 3(n=19)\end{array}$ & & & & Controls & & $\begin{array}{l}115(68-184) \\
115(68-200) \\
137(87-204)\end{array}$ \\
\hline
\end{tabular}

processing, short term memory, reading, and arithmetic. Owing to time limitations a shortened version of the Wechsler Intelligence Scale for Children (WISC:R $)^{7}$ was used to assess the patients only. The similarities, arithmetic, vocabulary, and digit span scaled scores were pro-rated to provide an estimate of verbal intelligence quotient(IQ), and block design, object assembly, and coding were pro-rated to measure performance IQ. These subtests have been found to account for a sizeable proportion of the variance in verbal and performance IQs. ${ }^{8}$ Measures of behavioural disturbances were obtained using Rutter behaviour questionnaires. ${ }^{910}$ These were completed by the parents and teacher of each child. A school report of each child's attainments and attendance was also obtained.

\section{Results}

Results of the BAS and WISC:R (which correlated appreciably, $\mathrm{r}=0.83, \mathrm{P}<0.001$ ) showed that the mean IQ of the whole sample was within the normal range and that the distribution of IQ scores was normal. Of the patients, $7 \%$ had an IQ below 80 , a figure that does not differ from the theoretically expected rate of $8 \%$.
There were no significant differences between the three age groups in any of the treatment variablesnamely, radiotherapy and drugs received. As the patients were treated at 7 different centres on 6 different protocols the data were analysed for each variable separately. Results of the analysis of variance were not significant for the main effects of treatment centres or trials. Significant results were found for the main effects of sex $(P<0.005)$ and group $(P<0.004)$ but not for the sex $\times$ group interaction $(P<0 \cdot 57)$. Data inspection showed that boys in all age groups had significantly higher IQs than girls.

Comparison of groups of patients. Results of the analysis of variance showed significant differences between groups for the WISC:R full scale, verbal, and performance scales (see Table 2). Group comparisons showed no significant difference between groups 2 and 3 on all three scales, but both groups scored significantly higher than group 1 $(P<0.05)$. Results of the BAS were similar but did not reach such a high degree of significance $(P<0.07)$. We believe this result was mainly due to the fact that the BAS does not include the arithmetic score in calculating IQ whereas the WISC:R does,

Table 2 Average intelligence quotients for three age groups of patients

\begin{tabular}{|c|c|c|c|c|c|c|c|}
\hline & & \multicolumn{3}{|c|}{ Group } & \multirow{2}{*}{$\begin{array}{l}\text { Degree of } \\
\text { freedom }\end{array}$} & \multirow{2}{*}{$\begin{array}{l}\text { Variance } \\
\text { ratio }\end{array}$} & \multirow[t]{2}{*}{$P$} \\
\hline & & 1 & 2 & 3 & & & \\
\hline BAS IQ & $\begin{array}{l}\text { No of patients } \\
\left\{\begin{array}{l}\text { Mean } \\
\text { SD }\end{array}\right.\end{array}$ & $\begin{array}{l}40 \\
96 \cdot 3 \\
14 \cdot 9\end{array}$ & $\begin{array}{l}38 \\
102 \cdot 8 \\
15 \cdot 7\end{array}$ & $\begin{array}{l}39 \\
103 \cdot 3 \\
13 \cdot 8\end{array}$ & 2,114 & $2 \cdot 73$ & 0.07 \\
\hline $\begin{array}{l}\text { WISC:R } \\
\text { Full Scale IQ }\end{array}$ & $\begin{array}{l}\text { No of patients } \\
\left\{\begin{array}{l}\text { Mean } \\
\text { SD }\end{array}\right.\end{array}$ & $\begin{array}{l}36 \\
94 \cdot 6 \\
16 \cdot 4\end{array}$ & $\begin{array}{l}41 \\
104 \cdot 9 \\
19 \cdot 1\end{array}$ & $\begin{array}{l}39 \\
105 \cdot 2 \\
17 \cdot 1\end{array}$ & 2,113 & $4 \cdot 35$ & 0.02 \\
\hline Verbal IQ & $\left\{\begin{array}{l}\text { Mean } \\
\text { SD }\end{array}\right.$ & $\begin{array}{l}95 \cdot 2 \\
15 \cdot 4\end{array}$ & $\begin{array}{l}106 \cdot 9 \\
18 \cdot 5\end{array}$ & $\begin{array}{l}105 \cdot 4 \\
17 \cdot 9\end{array}$ & 2,113 & 5.01 & 0.01 \\
\hline Performance IQ & $\left\{\begin{array}{l}\text { Mean } \\
\text { SD }\end{array}\right.$ & $\begin{array}{l}94 \cdot 8 \\
17 \cdot 1\end{array}$ & $\begin{array}{l}101 \cdot 4 \\
18 \cdot 7\end{array}$ & $\begin{array}{l}104 \cdot 3 \\
15 \cdot 4\end{array}$ & 2,113 & 3.02 & 0.05 \\
\hline
\end{tabular}


Table 3 Average scores in Wechsler subtests for three age groups

\begin{tabular}{|c|c|c|c|c|c|c|}
\hline & \multicolumn{3}{|l|}{ Group } & \multirow{2}{*}{$\begin{array}{l}\text { Degree of } \\
\text { freedom }\end{array}$} & \multirow{2}{*}{$\begin{array}{l}\text { Variance } \\
\text { ratio }\end{array}$} & \multirow[t]{2}{*}{$P$} \\
\hline & $1(n=36)$ & $2(n=41)$ & $3(n=39)$ & & & \\
\hline $\begin{array}{l}\text { Similarities } \\
\text { Arithmetic } \\
\text { Vocabulary } \\
\text { Digit span } \\
\text { Block design } \\
\text { Object assembly } \\
\text { Coding }\end{array}$ & $\begin{array}{r}9 \cdot 4 \\
8 \cdot 3 \\
10 \cdot 4 \\
8 \cdot 6 \\
9 \cdot 5 \\
8 \cdot 7 \\
9 \cdot 0\end{array}$ & $\begin{array}{r}12 \cdot 6 \\
10 \cdot 6 \\
12.4 \\
9 \cdot 1 \\
10 \cdot 6 \\
10 \cdot 6 \\
8 \cdot 9\end{array}$ & $\begin{array}{r}12 \cdot 1 \\
10 \cdot 6 \\
11 \cdot 0 \\
9 \cdot 9 \\
11 \cdot 8 \\
10.7 \\
9.7\end{array}$ & $\begin{array}{r}2,112 \\
2,113 \\
2,99 \\
2,109 \\
2,113 \\
2,110 \\
2,110\end{array}$ & $\begin{array}{l}8 \cdot 69 \\
6 \cdot 14 \\
4 \cdot 34 \\
1 \cdot 68 \\
4 \cdot 31 \\
4 \cdot 34 \\
0 \cdot 97\end{array}$ & $\begin{array}{l}0.003 \\
0.003 \\
0.02 \\
\text { ns } \\
0.02 \\
0.01 \\
\text { ns }\end{array}$ \\
\hline
\end{tabular}

and group 1 performed least well on arithmeticThere were no significant differences between groups 2 and 3 on four WISC:R subtests, namely similarities, arithmetic, block design, and object assembly. Both groups scored significantly higher than group 1 in these subtests. Table 3 gives results of the analysis.

A negative correlation was found between IQ and time since completing treatment in all groups combined $(r=-0 \cdot 24, \quad P<0 \cdot 004)$. A significant negative correlation was found between IQ and time since stopping treatment in Groups 1 and $2(r=$ -0.34 , and -0.31 respectively). A positive correlation was found for group $3(r=0 \cdot 14)$ but this was not significant. As group 1 was found to have stopped treatment for appreciably longer than groups 2 and 3, who did not differ from each other in this respect, the analysis reported in Table 2 was repeated with each of the dependent variables regressed against log time since stopping treatment. The three groups were then combined and a stepwise regression analysis was carried out to examine the relation between age, IQ, and time since stopping treatment. Table 4 shows the results of the stepwise analysis; they were similar to those reported above. Even after partialling out time since completing

Table 4 Summary of forced stepwise regression analysis

\begin{tabular}{|c|c|c|c|c|}
\hline Variable & Order & $\begin{array}{l}\text { Multiple } \\
\text { correlation } \\
\text { coefficient }\end{array}$ & $\begin{array}{l}\text { Variance } \\
\text { ratio }\end{array}$ & $\boldsymbol{P}$ \\
\hline \multicolumn{5}{|l|}{ WISC:R: } \\
\hline Full Scale IQ & $\begin{array}{l}\text { Log time off* } \\
\text { Age at irradiation }\end{array}$ & $\begin{array}{l}0 \cdot 27 \\
0 \cdot 32\end{array}$ & $\begin{array}{l}5 \cdot 87 \\
3 \cdot 50\end{array}$ & $\begin{array}{l}0.02 \\
0.06\end{array}$ \\
\hline Verbal IQ & $\left\{\begin{array}{l}\text { Log time off* } \\
\text { Age at irradiation }\end{array}\right.$ & $\begin{array}{l}0.29 \\
0 \cdot 33\end{array}$ & $\begin{array}{l}7 \cdot 05 \\
2 \cdot 91\end{array}$ & $\begin{array}{l}0.01 \\
0.09\end{array}$ \\
\hline Performance IQ & $\left\{\begin{array}{l}\text { Log time off* } \\
\text { Age at irradiation }\end{array}\right.$ & $\begin{array}{l}0 \cdot 22 \\
0 \cdot 28\end{array}$ & $\begin{array}{l}3 \cdot 34 \\
3 \cdot 69\end{array}$ & $\begin{array}{l}0.07 \\
0.06\end{array}$ \\
\hline \multicolumn{5}{|l|}{ BAS : } \\
\hline Full Scale IQ & $\left\{\begin{array}{l}\text { Log time off* } \\
\text { Age at irradiation }\end{array}\right.$ & $\begin{array}{l}0 \cdot 25 \\
0 \cdot 28\end{array}$ & $\begin{array}{l}5 \cdot 44 \\
1 \cdot 75\end{array}$ & $\begin{array}{l}0.02 \\
0.19\end{array}$ \\
\hline
\end{tabular}

* Log time since completing treatment.
Table 5 Comparison between 64 patients and siblings

\begin{tabular}{ccc}
\hline & Patients & Siblings \\
\hline \multicolumn{3}{c}{ Average BAS IQ } \\
Groups: & & \\
$1 \quad(\mathrm{n}=22)$ & $95 \cdot 2^{*}$ & $109 \cdot 4$ \\
$2 \quad(\mathrm{n}=22)$ & $101 \cdot 9^{*}$ & $114 \cdot 9$ \\
$3 \quad(\mathrm{n}=20)$ & 108 & $111 \cdot 2$ \\
Total $\quad(\mathrm{n}=64 \ddagger)$ & $101 \cdot 3^{*}$ & $111 \cdot 8$ \\
& & \\
Subtests $\$:$ & Average BAS subtest scores \\
Digit recall & & \\
Matrices & $46 \cdot 3 \dagger$ & $52 \cdot 1$ \\
Similarities & $49 \cdot 6^{*}$ & $55 \cdot 6$ \\
Information processing & $53 \cdot 1 \dagger$ & $56 \cdot 4$ \\
\hline
\end{tabular}

$* \mathbf{P}=0.001$, two tailed values used. $\dagger \mathbf{P}=0.02$, two tailed values used. $\ddagger$ Three patients scored 0 in speed of information processing, which rendered IQ incalculable. $\S \mathrm{Mean}=50, \mathrm{SD}=10$.

treatment, significant partial correlations remain between age at irradiation and WISC:R full scale and performance IQs.

Comparison of patients with controls. No significant differences were found between patients who had siblings tested and those who did not. The comparison between patients and their sibling controls showed that the patients had an average BAS IQ $10 \cdot 5$ points lower than their siblings, $(t(60)=5 \cdot 15$, $\mathbf{P}<0.001)$. Patients in groups 1 and 2 had significantly lower IQs than their controls, but patients in group 3 did not differ from their controls (Table 5). The patients scored significantly lower than the controls for short term memory, non-verbal reasoning, and speed of information processing.

As the results consistently showed, patients in group 1 had lower intellectual abilities than those in groups 2 and 3. Further analysis was, therefore, carried out to compare their performance with that of children matched for age, sex, and socioeconomic background. These children were selected from all the siblings assessed in this study, and 25 matched pairs were identified. The patients' average IQ was found to be 97.9 , and the matched controls had an average IQ of $113.5(t(24)=4.9, \mathrm{P}<0.01)$. 
Attainment. Results of the BAS reading test showed that $42 \%$ of the patients and $15 \%$ of the siblings were reading at a level below the 25th centile for their age group. Forty one percent of group 1, 59\% of group 2, and $20 \%$ of group 3 fell into this category. Of all the patients, $14 \%$ were identified as having specific reading retardation-that is, having reading ages 30 months or more below those predicted on the basis of their chronological age and intelligence. This is significantly higher than the expected rate of $5 \%\left(\chi^{2}=7 \cdot 53, P<0.01\right)$. Three siblings $(4 \%)$ were found to have specific reading retardation of this degree. (The multiple regression equation used for predicting reading age using BAS IQ and age was $(1.07 \times \mathrm{CA})+(.98 \times \mathrm{IQ})-105.66)$. This was obtained from a sample of 96 healthy children with mean age 107 months, mean IQ 111 , mean reading age 118 months). Yule et al., using a different reading test, found that fewer than $5 \%$ of their sample of normal 6-12 year olds had specific reading retardation. ${ }^{11}$ Results of the arithmetic test showed that $32 \%$ of the patients and $14 \%$ of the siblings scored below the 25th centile for their age group. Fifty three percent of group 1, 22\% of group 2, and $24 \%$ of group 3 were backward in their arithmetic skills.

Behaviour. Results of the Rutter Parent Behaviour Questionnaire showed that $16 \%$ of the patients and $13 \%$ of the siblings scored above the cut off point for behavioural deviance. Results of the Rutter Teacher Behaviour Questionnaire showed that $17 \%$ of the patients and $6 \%$ of the siblings scored above the cut off point for behavioural deviance as rated by teachers $\left(\chi^{2}=3 \cdot 29, P<0 \cdot 1\right)$. These results do not differ greatly from those reported in studies in the general population.9 ${ }^{910}$ School attendance was rated as good to excellent in most cases. Only 6 patients $(5 \%)$ were said to show poor attendance.

\section{Discussion}

Results of this study showed that children treated for acute lymphoblastic leukaemia with a combination of chemotherapy and radiotherapy were functioning within the normal range of intelligence several years after completing treatment. Similar findings were reported by Moss et al. $^{2}$ and Eiser and Lansdown. ${ }^{1213}$ Our patients, however, were found to have higher IQs than those evaluated by Eiser using the same tests. Apart from the fact that our sample was much larger, our patients were older and had stopped receiving treatment for a longer period before the study.
The large discrepancy in IQ between patients and their own siblings, who share the same genetic and environmental background and who would be expected to have comparable IQs, suggests that the drop in IQ among the patients is mainly due to the effects of the treatment or the disease itself, or both. The treatment usually comprises two or three years of chemotherapy and a course of prophylactic irradiation of the CNS and intrathecal methotrexate. There have been several reports of neurological and psychological complications arising from treatment for acute lymphoblastic leukaemia. ${ }^{1-312-16}$ Overt neurological deterioration has been seen in children without previous leukaemia of the CNS who received cranial irradiation followed by parenteral methotrexate in moderate doses, rather than intrathecal or oral methotrexate. Preliminary results of a prospective study of 36 patients receiving oral methotrexate and 31 patients receiving intramuscular methotrexate have shown that one year after diagnosis patients receiving oral methotrexate show an average increase in IQ scores (113.5 up to 115.9) and patients receiving intramuscular methotrexate show an average decline in IQ $(110 \cdot 8$ down to $108 \cdot 4)$ (Jannoun and Chessells in preparation).

Several attempts have been made to isolate the effects of irradiation of the CNS from the effects of chemotherapy and disease related variables. ${ }^{1-3} 1217$ In spite of the small size of the samples and the methodological differences when considered collectively these studies strongly suggest that irradiation of the CNS pioduces some loss of intelligence among younger patients. Only one study has failed to show significant differences between patients treated by irradiation of the CNS and those not treated in this way, ${ }^{17}$ but, even here, patients with acute lymphoblastic leukaemia were found to have some learning deficits.

In view of these reports, which have indicated that prophylaxis of the CNS may cause neuropsychological damage, less toxic but equally effective alternatives are being sought. Nesbit et al. ${ }^{18}$ have found that the reduction from 2400 rads to 1800 rads did not result in a significant increase in the incidence of CNS, or bone marrow relapse, or death. It remains to be seen whether the lower dose affects the intellectual development of patients with acute lymphoblastic leukaemia any less than the higher dose.

Results of the present study show a significant correlation between IQ and age at irradiation even when the effects of time since completing treatment were partialled out. Patients who were irradiated under the age of 3 years were found to have lower IQs than those who received treatment at an older age and than healthy children matched for 
age, sex, and parental occupation. These results confirm and extend the findings of previous studies. ${ }^{1-3}$ 12-13 Two other findings in this study point to the importance of age at receiving treatment for acute lymphoblastic leukaemia in determining the extent to which a child's intellectual abilities are affected. First, only patients who were treated when aged 7 years or older were found to have IQs comparable to their own siblings. Secondly, a significant negative correlation was found between IQ and time since stopping treatment for patients who were treated under the age of 7 , suggesting that these patients show greater impairment the longer they survive in remission after completing treatment. One possible explanation is that the adverse effects of the treatment are delayed and become apparent several years later. Evidence from our own prospective studies of patients with acute lymphoblastic leukaemia (Jannoun and Chessells in preparation) and from the work of others ${ }^{3}$ does not support this because a decline in intellectual functions has been observed during the first two years of treatment. Another possible explanation is that treatment for acute lymphoblastic leukaemia interferes with and arrests the normal intellectual growth of children. Consequently, the gap between a child's performance and that of his normal peers becomes wider the longer he survives, although his performance does not deteriorate.

We found a large proportion of the patients to be backward in reading and arithmetic. This might be a result of interrupted schooling during treatment at a critical stage for acquiring reading skills. Early remedial help during this stage might prove to be beneficial to patients in whom acute lymphoblastic leukaemia is diagnosed after they have started school. Disrupted schooling, however, cannot fully account for the backwardness of patients in group 1 as most of them had completed treatment before starting school and only one child in this age group showed poor school attendance. Impaired specific cognitive functioning is a more likely explanation in this group, in which $41 \%$ of patients were reading below the 25th centile for their age group. Further research is needed to identify patients with acute lymphoblastic leukaemia with cognitive deficits who may benefit from specialised remedial education. This seems necessary in view of the findings of brain investigations by computed tomography, which have shown mineralising microangiopathy with dystrophic calcification in asymptomatic patients with acute lymphoblastic leukaemia. ${ }^{19}$ Price and Birdwell have found that patients under the age of 10 years at the time of irradiation run the greatest risk of developing microangiopathy. ${ }^{19}$
Brain lesions were found to be significantly more prevalent among patients under the age of 5 years at the time of irradiation. A close association was also found between survival time after irradiation and the development of vascular lesions.

Our results show that patients treated for acute lymphoblastic leukaemia when they are below the age of 3 years show greater intellectual impairment than patients receiving treatment at an older age, although the latter show some impairment when compared with their own siblings. This has implications for the management and education of patients with acute lymphoblastic leukaemia, especially of those in the younger age group. The possibility of delaying prophylactic irradiation of the CNS until the age of 3 years should be considered, and the search for alternative methods of prophylaxis of the CNS that will be equally effective but less neurotoxic should continue. Parents and teachers of young children should be alerted to the possibility of learning difficulties so that specialised remedial help can be arranged at an early stage if this seems to be needed.

I am grateful to Dr Judith Chessells and to Professor Philip Graham for their help and advice. My thanks to Drs V Broadbent, O B Eden, J S Lilleyman, D Mainwairing, J R Mann, J Martin, and E N Thompson for their cooperation and support. This study was supported by the Medical Research Council of Great Britain.

\section{References}

1 Eiser C. Intellectual abilities among survivors of childhood leukaemia as a function of CNS irradiation. Arch Dis Child 1978;53:391-5.

2 Moss HA, Nannis ED, Poplack DA. The effects of prophylactic treatment of the central nervous system on the intellectual functioning of children with acute lymphocytic leukemia. Am J Med 1981 ;71:47-52.

3 Meadows AT, Gordon J, Massari D, Littman P, Fergusson J, Moss K. Declines in IQ scores and cognitive dysfunction in children with acute lymphocytic leukaemia treated with cranial irradiation. Lancet 1981;ii:1015-8.

4 McLennan IC, Peto J, Kay HE. Analysis of treatment in childhood leukaemia. V. Advantage of reduced chemotherapy during and immediately after cranial irradiation. Br J Cancer 1977;36:625-33.

5 Chessells J, Ninane J, Tiedmann K. Present problems in management of childhood lymphoblastic leukaemia: experience from the Hospital for Sick Children, London, In: Neth R, Gallo RC, Graff T, Mannweiler K. Winkler K, eds. Modern trends in human leukaemia. IV. Berlin: Springer, 1981.

6 Elliott C, Murray D, Pearson L. British ability scales. Windsor: NFER Publishing Company, 1978.

7 Wechsler D. Wechsler intelligence scale for children: revised. New York: Psychological Corporation, 1974.

8 Maxwell A. A factor analysis of the Wechsler intelligence scale for children. Br J Educ Psychol 1959;29:237-41. 
9 Rutter M. A children's behaviour questionnaire for completion by teachers: preliminary findings. $J$ Child Psychol Psychiatry 1967;8:1-11.

10 Rutter M, Tizzard J, Whitmore K. Education, health and behaviour. London: Heinemann, 1970.

11 Yule W, Lansdown R, Urbanowicz MA. Predicting educational attainment from WISC: $R$ in a primary school sample. Br J Clin Psychol 1982;21:43-6.

12 Eiser C. Effects of chronic illness on intellectual development: a comparison of normal children with those treated for childhood leukaemia and solid tumours. Arch Dis Child 1980;55:766-70.

13 Eiser C, Lansdown R. Retrospective study of intellectual development in children treated for acute lymphoblastic leukaemia. Arch Dis Child 1977;52:525-9.

14 Price RA, Jamieson PA. The central nervous system in childhood leukemia. II. Subacute leukoencephalopathy. Cancer 1975;35:306-18.

15 McIntosh S, Klatskin EH, O'Brien RT, et al. Chronic neurologic disturbance in childhood leukemia. Cancer $1976 ; 37: 853-7$.
16 Aur RJA, Simone JV, Verzosa MS, et al. Childhood acute lymphocytic leukemia: Study VIII. Cancer 1978; 42:2123-34.

17 Soni SS, Marten GW, Pitner SE, Duenas DA, Powazek M. Effects of central nervous system irradiation on neuropsychologic functioning of children with acute lymphocytic leukaemia. $N$ Engl J Med 1975;293:113-8.

18 Nesbit ME, Jr, Sather HN, Robinson LL, et al. Presymptomatic central nervous system therapy in previously untreated childhood acute lymphoblastic leukaemia: comparison of $1800 \mathrm{rad}$ and $2400 \mathrm{rad}$. Lancet 1981 ; : 461-6.

19 Price RA, Birdwell DA. The central nervous system in childhood leukemia. III. Mineralizing microangiopathy and dystrophic calcification. Cancer $1978 ; 42: 717-28$.

Correspondence to Dr L Jannoun, Department of Child Psychiatry, Hospital for Sick Children, Great Ormond Street, London WCIN $3 J H$.

Received 22 September 1983 